\title{
A Framework for Designing Usable Localised Business Websites
}

\author{
Ali H. Al-Badi ${ }^{1}$ and Pam J. Mayhew ${ }^{2}$ \\ ${ }^{1}$ Information Systems Department, SQU, Oman \\ ${ }^{2}$ School of Computing Sciences, UEA, Norwich, UK
}

\begin{abstract}
Website localisation is the process of adapting the linguistic and cultural content of an internationalised web design for a specific target audience in a specific locale. With the advent of globalisation, website localisation is becoming a powerful way to attract online customers in a global market. Hence, the main driving force behind such moves is financial, but with a strong motivation towards cross-cultural sensitivity.
\end{abstract}

The primary aim of this research therefore is to explore the design of websites for different cultures. It seeks to provide an outline of the current and relevant literature with regard to cultural usability and user interface design. It also aspires to develop and experiment with a Cultural User Interface (CUI) profile. The intention is to create a framework for designing usable localised websites. To achieve these ends, the research employs various methodologies. These include descriptive/interpretive studies of the literature and previous studies by academics and industrial institutions. Furthermore it utilises surveys and case studies among Internet users, web designers, and web production companies in the target cultures (Arab and British). In the process a website has been redesigned according to the guidelines of a newly built framework within the context of an action research approach. Finally, by comparing the original and the redesigned websites, a comparative evaluation has been carried out.

The research findings contribute to the general field of software/web localisation and personalisation. They also provide academics and industry with information on the degree to which cultural localisation is needed to ensure usability. In addition, they highlight the extent to which users' cultural background and perceptions influence their preferences and hence the acceptance of the virtual world of online user interfaces. The main findings of this research highlight the necessity to understand both the target culture and the needs of the business commissioning the website. They also show the value of design consistency (navigation, layout, interaction, graphics and colours, etc). Furthermore the researchers were able to identify a drawback in web designers' current practices in the investigated countries, in terms of their limited utilisation of existing guidelines for the exploitation of intercultural usability, accessibility, knowledge, tools and methods.

Key words: Websites, Local culture, Localized business websites, Globalization, Internationalization

Copyright (C) 2010 Ali H. Al-Badi , Pam J. Mayhew. This is an open access article distributed under the Creative Commons Attribution License unported 3.0, which permits unrestricted use, distribution, and reproduction in any medium, provided that original work is properly cited. Author contact: Ali H. Al-Badi , e-mail: $\underline{\text { aalbadi@squ.edu.om }}$ 


\section{Introduction}

In order to localise to a particular market, designers need to know about its preferences, likes and dislikes, so they can provide cultural metaphors ${ }^{1}$, real world representation of the user interface objects, and also eliminates any culturally offensive material.

The importance of cultural effects on the perception of the content of a website has been discussed in the literature. The interface design is the most important element that the users see and interact with. Previous work by Evers and Day (Evers and Day, 1997) (based on the Technology Acceptance Model after (Davis, 1993)) has indicated that culture does indeed influence interface acceptance.

Issues like colours, graphics, signs and placement of web elements may have different connotations for people in different parts of the world. Audiences may differ in age, educational level, ethnic and religious background. In the future users might be able to use a personal user interface as described by Yeo (Yeo, 1996) or similar. As well as functioning properly, the website should be usable by all people, to the greatest extent possible, regardless of location, language, business practices, or cultural issues. For a website to be usable, the surface representation must correspond to something that is well known to the user. Some icons ${ }^{2}$ that are meaningful in North America may not be appropriate for other countries.

The existing guidelines, methods and tools are steps in the right direction; however, most studies of usability have taken place within North America and to a lesser extent in Western Europe. Hence they need to be broadened to meet the challenge of a global environment. What is needed is a framework to help designers/developers and/or evaluators to assess the usability of a website. This framework must consider all

1 In human-computer interface design, elements from the real world are used to represent the virtual world. This is done to help users out through reference to knowledge they already have from their everyday lives.

${ }^{2}$ Icons are small pictorial images that are used to represent system objects, applications, utilities and commands. the factors (challenges) that are involved in the process of localising websites. For a website to be successful outside North America, the designers must be aware of the factors that will ensure it is acceptable to other cultures. This research aims to identify such factors and construct a framework that will help in the design of a culturally acceptable website.

This paper explores the main terms under consideration; which are website usability, accessibility, globalisation, readability and cultural difference issues. It starts by defining website usability and highlights its importance, as well as the obstacles in achieving it coupled with the value of usability tools. This is followed by web usability guidelines and their limitations. Similarly, website accessibility definitions, tools and guidelines are explored. It also surveys readability formulas, highlighting their limitations and hence, seeks an alternative procedure in order to produce a text that is readable online. Furthermore, globalisation, cultural difference issues and cultural models are discussed in this context. Particular emphasis is put on the process of localising a website.

\subsection{Website Usability}

The term usability surfaced two decades ago to replace the term "user friendly". However, there are numerous definitions of web usability proposed by various individuals, some of which are as follows:

Nielsen (Nielsen, 1994) has divided usability into five different attributes. These are learnability, efficiency, memorability, rate of errors and satisfaction. Preece et al. (Preece et al., 1994) defined usability as "a measure of the ease with which a system can be learned or used, its safety, effectiveness and efficiency, and the attitude of its users towards it". Shneiderman (Shneiderman, 1998) defined usability as "a combination of characteristics oriented to the user, which are: easiness of learning, high speed of user task performance, low user error rate, subjective user satisfaction and user retention over time".

Web usability has also been defined as the degree of ease with which users can complete various tasks using a website interface with which they are unfamiliar (Alexander, 2009). Common tasks include: browsing and general site navigation, 
locating particular information, purchasing goods and services, submitting data via forms and participating in web based discussion groups. According to (Brinck et al., 2002) usability can be defined as the degree to which people (users) can perform a set of required tasks, and it is the product of several, sometimes conflicting, design goals including: functionally correct; efficient to use; easy to learn; easy to remember; error tolerant and subjectively pleasing.

ISO 9241-11 defines usability as "the extent to which a product can be used by specified users to achieve specified goals with effectiveness, efficiency and satisfaction in a specified context of use" (Kiviniemi, 2000). Keevil (Keevil, 1998) defined it as "how easy it is to find, understand and use the information displayed on a website". Usability is the measure of the quality of a user's experience when interacting with a product or system (Usability.gov, 2002).

From these, the author has developed a simple yet arguably more comprehensive definition of usability, as follows:

"Usability is the quality that indicates to what extent it is easy for all users of a website to interact with it in performing the required $\operatorname{task}(\mathrm{s}) "$.

Usability has always been accepted as a major contributor to the perceived success of a system. For web based systems, usability is absolutely critical. Jakob Nielsen puts this very succinctly in the following two quotations:

1) "Usability rules the web. Simply stated, if the customer can't find a product, then he or she will not buy it"; 2) "The web is the ultimate customer-empowering environment. He or she who clicks the mouse gets to decide everything. It is so easy to go elsewhere; all the competitors in the world are but a mouse click away" (Nielsen, 1999).

Website usability is widely recognised as the most important requirement for user acceptance. This requirement is especially critical for some websites, for example, for e-commerce websites; a customer dissatisfied as a result of poor usability is likely to become a competitor's customer. On the other hand, the user population is expanding in term of age, expectations, information needs, tasks, and user abilities.
Websites should accommodate all these variations over time.

Shneiderman (Shneiderman, 1998) argued that "Universal Usability will be met when affordable, useful, and usable technology accommodates the vast majority of the global population". Despite the recognition of the importance of usability for web based systems, some would argue that many websites today still fail the most basic tests of usability (Forrester Research, 2003). Appropriate website design and evaluation methods (for details see(Al-Badi, 2005)) help ensure that websites are usable (Nielsen and Mack, 1994). However, they are so numerous; it is hard to know which one(s) are best suited for a particular website. Nevertheless, there exist "usability tools" that, when used, can help in simplifying the matter to a great extent and lead to a usable website (for details about these tools see (Al-Badi, 2005)).

\subsubsection{Web Usability Guidelines}

The growing website usability expert community has formulated countless guidelines, and a subset of these is currently in common use. However, none sufficiently cover all possible variant constraints (Becker, 2002a).

Many of these guidelines have been based on developer expertise, project experiences, and subjective studies. Existing user interface design recommendations were extended to include designing user interfaces for the web (Shneiderman, 2000, Nielsen, 1999, Lynch and Horton, 1999). Those experienced in designing user interfaces provided heuristics or guidelines for designing web pages, often by identifying design layout, navigation, and performance issues associated with particular websites (Spool et al., 1999, Hurst, 1999, Flanders and Willis, 1998). Many of these guidelines were incomplete or too general to apply to the development of all websites (Becker, 2002b, Beirekdar et al., 2002).

Numerous online articles were published based on developer experiences, customer feedback, economic and marketing data regarding web use. In addition, there have been many websites that provide help to build a usable website(University of Rochester, 2009, Lynch and Horton, 1999), 
many papers published (Borges et al., 1996, Spool and Scanlon, 1997), many books (Nielsen and Mack, 1994), and some effort put into building a Web Usability Assessment Model (Becker and Berkemeyer, 2001). Furthermore, a framework and guideline definition language (GDL) for usability (automation) evaluation has been proposed in (Beirekdar et al., 2002). A brief summary of currently available "usability guidelines" is available in (Al-Badi, 2005).

The search for a web usability assessment model has been going on for some time. Jakob Nielsen devoted a whole section to this topic in his early book on the subject (Nielsen, 1994). Becker and Berkemeyer in (Becker and Berkemeyer, 2001) found that none of the existing heuristics or guidelines would satisfy the usability requirements for assessing localised websites, so they developed their own Web Usability model. This Web usability assessment model is made up of several key components: strategic goals of the organisation in using the web, localised target markets described collectively as a user profile, the computing environment typical of the localised market, and generic usability factors. In this model there are eleven usability factors: navigation, design standards, personalisation, design layout, performance, customer satisfaction, design consistency, reliability, security, information content, and accessibility (Becker, 2002b). It seems that the authors put great effort into producing their sets of usability guidelines. This work, however, stopped short of reaching the level of being a model, because a model is a representation of the real world. As such, its correctness should be verified. The authors did not show how they verified that it was a correct or a complete model; hence it should be regarded as a framework or simply another set of guidelines.

There are a number of international standards (ISO) for "Software Usability"; however, these standards are not especially dedicated to web usability. Rather, they focus more on software and graphical user interfaces in general, thus, they require some modification, adaptation, and extension. These standards include:

1. ISO 9241-11: "Guideline on Usability": defines usability in terms of effectiveness, efficiency, and satisfaction.

2. ISO 9126-1: "Quality Model": is concerned primarily with the definition of quality characteristics to be used in the evaluation of software products. It sets out six quality characteristics, which are intended to be exhaustive. These are: Functionality, Reliability, Usability, Efficiency, Maintainability and Portability (ISO 9126, 2002).

Although usability guidelines have proven useful, they still suffer from a number of shortcomings that impede their widespread use and reduce their usefulness. Some researchers have already outlined some of these real limitations (Vanderdonckt, 1999, Nielsen and Mack, 1994, Scapin et al., 2000). The main limitations are as follows: 1) The language used comes from various disciplines (e.g., cognitive modelling, psychology, human factors, ethnography), which may prevent web designers from easily understanding it and applying the guidelines correctly; 2) It is difficult to interpret when and how general guidelines need to be applied during the website lifecycle; 3) Almost all guidelines are based on one natural language (English) and one culture (North American).

\subsection{Website Accessibility}

Having read about "Usability" in the previous section, the reader might want to compare it with the buzzword "Accessibility". This section aims to shed light on the term "Accessibility" in order to show the relationship between "Usability" and "Accessibility". Generally, web accessibility refers to the degree to which web information is accessible to all human beings (e.g. disabled, able-bodied, old and young). That is, the goal of web accessibility is to allow universal access to information on the web, by all people but especially by people with disabilities (e.g. blindness, low vision, deafness, hard of hearing, physical disabilities or cognitive disabilities). In addition, the information must be accessible by automatic machine tools (e.g. site indexing tools, robots). This is nicely explained by Chuck Letourneau (Letourneau, 2003) who defines web accessibility to mean " ... anyone using any kind of web browsing technology must be able to visit any site and get a full and 
complete understanding of the information and must have the full and complete ability to interact with the site if that is necessary". The term accessible design is used to refer to design intended to maximise the number of potential customers who can readily use a website. Accessible design can impact market size and market share through consideration of the functional needs of all consumers, including those who experience functional limitations as a result of ageing or disabling conditions. A functional limitation describes a reduced sensory, cognitive, or motor capability associated with human ageing, temporary injury, or permanent disability that prevents a person from communicating, working, playing, or simply functioning in an environment where other people in the population can function (Monterey Technologies Inc, 1996).

Accessible web design entails ensuring that web pages are "user-friendly" in the broadest sense for all those visiting a site. This includes layout, readability, colour choice and browser-independence, as well as considering the requirements of those using adaptive or alternative technology (Forrester Research, 2003). It is worth mentioning the relationship between accessibility and usability; they are closely related, as they both improve satisfaction, effectiveness, and efficiency of users. But while accessibility is aimed at making the website open to a wider user population, usability is aimed at making the target population of the website happier, more efficient, and more effective. Basically, web usability is about making things more intuitive and user-friendly. Therefore, usability implies accessibility (Brajnik, 2000), where accessibility is defined as "the website's ability to be used by someone with disabilities".

The importance of web accessibility can be realised from the following reasonings: "The power of the web is in its universality. Access by everyone regardless of disability is an essential aspect" (Smillie, 2001). "Given the explosive growth in the use of the World Wide Web for publishing, electronic commerce, lifelong learning and the delivery of government services, it is vital that the web be accessible to everyone" (Bill Clinton, 1997, as quoted in (Paciello, 2000)). In addition to the obvious reasons for making commercial and government websites conform to accessibility guidelines, the available statistics highlight the importance of such effort. Exploring these statistics, it was found that there are more than 750 million people worldwide with disabilities (Computer Weekly, 2001). In the UK alone, there are 1.7 million blind and partially sighted people (UK RNIB, 2002a). In Saudi Arabia, the total numbers of disabled citizens is 720,000, which represents $4 \%$ of Saudi's population. In addition, the rate is expected to increase by 5\% annually (Riyadh city reporter, 2004). According to the 1995 census, the number of disabled people in Oman reached 31,510 (Ministry of Social Development, 1995). However, the W3C estimates that more than $90 \%$ of all sites on the WWW are inaccessible to disabled users (Boldyreff, 2002). These statistics highlight the extent of effort needed in order to allow the disabled peoples to get the benefit of online information and commercial websites.

We are not all the same (Hofstede, 1991)"One size does not fit all", so web designers have to accommodate the differences. "Since most websites fail to accommodate people with disabilities, these websites have to be re-engineered to achieve accessibility. As we move towards a highly connected world, it is critical that the web be usable by anyone, regardless of individual capabilities and disabilities"-Tim Berners-Lee, Director of the W3C and inventor of the World Wide Web (Computer Weekly, 2001). Moreover, making information accessible to all customers is becoming a critical issue for different reasons, some of which are: 1) fairness to people with disabilities demands that they to have access to information as everybody else does; 2) it is the law in a number of countries around the world such as USA, UK and other European Union Countries; 3) taking into account the large number of people with disabilities, it makes good business sense to meet their needs in term of making all online information accessible to them.

In compliance with all the above, many countries, started putting some effort in this regard. For example, in the USA, the accessibility of information on the web has been well regulated: Section 255 of the Telecommunications Act 1996 regulates the accessibility of Internet Telephony (Federal Communications Commission, 2004). The 1998 Amendments to the Rehabilitation Act (US Section 508, 2009) added significant 
accessibility requirements for the design of electronic and information technology, including accessible web design.

The European Union (EU) countries, working together, have established the EU Web Accessibility Initiative (Information Society, 2002). Individual member states, for example, the UK, with the "UK Disability and Discrimination Act 1995", are making great efforts to legalise the accessibility of online information resources. The British government is conducting a "Campaign for Good Web Design" (UK RNIB, 2002b) to further encourage the effort towards web accessibility.

\subsubsection{Web Accessibility Guidelines}

Although web accessibility is a relatively new concept it has started getting wide attention amongst the professionals in the field. In addition to individual efforts (Beirekdar et al., 2002, Boldyreff, 2002), the participants can be divided into four categories: Government, Universities, Institutions and Companies (for more details see (Al-Badi, 2005)). There is no lack of guidelines, standards and legislations; however a mechanism for implementing them, in real life, has yet to emerge. The next section discusses tools that implement these guidelines, standards and legislations (for more details see (Al-Badi, 2005)).

\subsubsection{Website Usability and Accessibility Tools}

Numerous tools exist to determine whether or not a website adheres to various web usability/accessibility guidelines. These tools can provide useful feedback to the web designers and maintainers. In addition, these tools can assist in the repair and enhancement process of a website. There are websites that provide a selection of these tools with a description of the functionality of each tool(Thatcher, 2002, WEBAIM, 2009, Brown, 2002, Graves, 2001, NIST, 2004, Becker, 2002c, Hower, 2009, W3C, 2002b). Some of the better-known tools are listed by (Al-Badi, 2005).

There are a number of studies on automating the Web usability/accessibility evaluation process, aimed at examining the usefulness and effectiveness of the existing tools. For example, Brajnik (Brajnik, 2000) presented a survey of automatic usability evaluation tools for websites. These tools consider a large set of properties depending on attributes and not on the context of websites. He concluded that, in particular, those tools supporting repair actions have the potential to dramatically reduce the time and effort needed to perform maintenance activities. A recent study (Ivory and Chevalier, 2002) examined the effectiveness of the WatchFire Bobby (Watchfire, 2002), W3C HTML Validator (W3C, 2002a), and UsableNet LIFT automated evaluation tools (UsableNet.com, 2002). They concluded that although the tools helped designers to identify a large number of potential problems, designers were not effective in interpreting and applying the guidelines. Furthermore, the modifications that designers made based on the tools did not improve user performance or ratings.

\subsubsection{Website Readability}

Readability on websites should be given high priority. Web documents have very different characteristics from newspaper articles or pages in a textbook. Web designers are required to design web pages that attract surfers, retain and convert them to loyal customer. Readability is concerned with the extent to which a piece of text is easy for the target reader to read. A proficient reader is likely to be bored by simple repetitive texts. An incompetent reader will soon become discouraged by texts which he/she finds too difficult to read. This is likely to happen when the text contains complex sentence structures, long words, or too much material with entirely new ideas. The term readability refers to all the factors that affect reading and understanding a piece of text. These factors include: the readers interest and motivation, page layout (e.g. foreground/background colour, spacing between lines and objects), text affects (e.g. font type faces, size and styles) etc., the quality of the user's monitor as well as the actual composition of the website content (Lee, 1999).

Readability formulas (also called readability indices or metrics) were first developed in the 1920s in the United States. For more many years, readability formulas have helped teachers, librarians, and parents match books to students in that country. They used to analyse text and predict which materials can be comprehended by 
individual readers. As far as the researchers are aware, there is no equivalent to such formulas for the Arabic language.

Most websites use text as a common way of communication because it downloads quickly and is understood by all existing browsers (Allen, 2002). Previous studies, research and practitioners in the fields of "web usability" and "writing for the web" found that writing for the web is different from writing for hardcopy (print). This is due to the fact that people rarely read web pages word by word; instead, they scan the page content. It was found that $79 \%$ of users always scan any new page they come across and only $16 \%$ read word by word (Morkes and Nielsen, 1997b, Thomason, 2009, Nielsen, 2005, Nielsen, 1997b) Reading from computer screens is 25\% slower than from paper. Web content should have $50 \%$ of the word count of its paper equivalent (Nielsen, 1997c, Morkes and Nielsen, 1997a). (Dillon et al., 1992) emphasised that reading on a screen is substantially slower than reading print and accuracy is lessened for cognitively demanding tasks. They also suggested that visual fatigue and reduced levels of comprehension is more likely to result from reading from screen and readers preferred good hard copy (print) to screen displays. There was almost consensus among the usability experts regarding the need for different style of writing when composing a web document. Online documents need to be concise, scanable and objective (Morkes and Nielsen, 1997a). Therefore, experts in the field formulated a set of guidelines for writing for the web. A summary of such guidelines is available in (Al-Badi, 2005). A readability formula is a method of testing the level of reading skill needed to be able to read a particular piece of text. Readability formulas are mathematical equations that correlate various document features with a standard measure of reading comprehension. The document features can include number of letters per word, number of syllables per word and number of words per sentence. Most of the current readability formulas express the readability level as a grade level or as years of education. However, many researchers believe that the way readability formulas predict the readability of a document is inadequate. As a matter of fact, readability formulas might be counterproductive because they focus the writer's attention on words and sentences and draw attention away from other readability issues. Nevertheless, hundreds of readability indexes/formulas exist. Many online resources describe different kinds of readability formulae (Hill, 1997, Nielsen, 1997c, Weitzel, 2003, Miller, 2004). For details see the report in (Al-Badi, 2002, Al-Badi, 2005) highlights the most popular formulas.

\subsubsection{Website Globalisation}

When the site audience is the whole world, how can its content be made accessible to the non-American, non-English-speaking people who have different cultural values and expectations? Does the translation of a website from one language to another solve the problem? Becker and Crespo argued that the basis of support for multicultural websites is quite complex and cannot be viewed as a direct translation of textual content from one language to another (Becker and Crespo, 2001). In addition to the inadequacy of the translation, it is also a very expensive process. This is because any changes to the home language site will require that related changes are made to the foreign language sites, so that the translation issues never end. It can involve many types of materials, including technical documents, marketing materials, market research, sales information, product literature, price lists, and even competitor information. Moreover, application server and content management software were initially developed for the monolingual US market and often do not work smoothly with non-English character sets. Such issues are obstacles for international web designers in producing usable localised websites. Therefore, it is not only because translation is expensive and inadequate but also because there are other issues that need to be considered. These relate to culture, real-world experience, language etc. Cultural Difference Issues section later). Such realisation led to the emergence of the term "Globalisation" which is defined below.

\subsubsection{Globalisation}

"A truly globalised website serves every visitor with the same quality experience regardless of location, language, business practices, or cultural issues" (Izar.com, 2002). The idea of globalisation can be visualised as shown in Figure 1 below. 


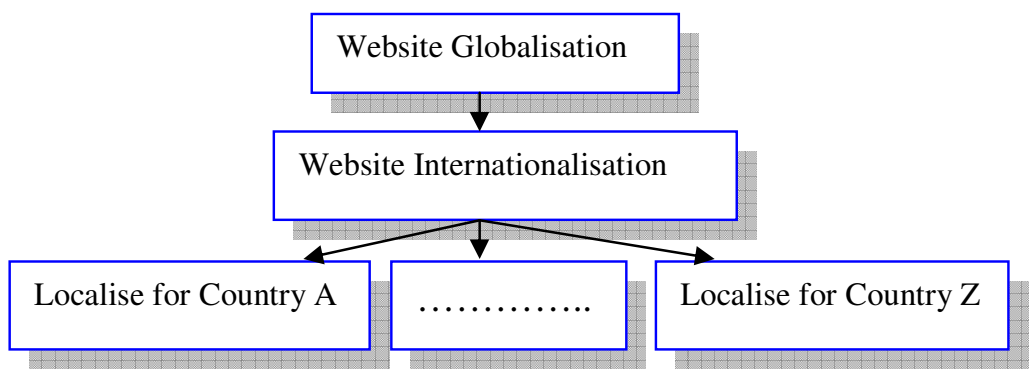

Figure 1: Website Globalisation Visualisation

Globalisation encompasses the whole process of creating a product with versions for users in different countries, from the first specification through adaptation to local markets. However, some software engineers use the term interchangeably with the word "Internationalisation" (Hars, 1996). Today's e-business requires an infrastructure that will accelerate globalisation and provide a standard platform that all parties can use to manage and streamline the process (Uniscape, 2002).

\subsubsection{Internationalisation (I18N $\left.{ }^{3}\right)$}

According to Nielsen (Nielsen, 1999), Internationalisation refers to having a single design that can be used worldwide. It is the process and philosophy of making software/website portable to other locales. For successful localisation, products/website must be technically and culturally neutral. Effective internationalisation reduces the time and resources required for localisation. In other words, internationalisation abstracts out local details, localisation specifies those details for a particular locale.

Although logically it is the first step in the globalisation process, internationalisation is often done after the company has done a localised version. Internationalisation involves designing an e-business framework or web architecture that is culturally neutral. The creation of a linguistic and culturally neutral framework is the first critical step in the globalisation

${ }^{3}$ I18N- Stands for Internationalization (where $\mathrm{I}$ and $\mathrm{N}$ are separated by 18 characters). process. Internationalisation, then, prepares website and e-commerce applications to function seamlessly across diverse cultural backgrounds and business rules, which can be loaded as needed for appropriate audiences (Uniscape, 2002). In other words Internationalisation is design consistency (the same "look and feel") across localised websites achieved by extracting language and culturally dependent elements i.e. creating a culturally sensitive website.

\subsubsection{Localisation (L10N $\left.{ }^{4}\right)$}

According to Nielsen (Nielsen, 1999), localisation refers to making an adapted version of the Internationalised design for a specific locale. Localisation involves the process of adapting linguistic and cultural content to specific target audiences in specific "locales." "Locale" is the name for specific linguistic, cultural and business rules for a given target audience. For example, the Spanish language in Mexico is different from the Spanish spoken in Spain, and the same conditions apply for the currency and other business rules.

While some may use this term to include the text translation process, it also covers making sure that the graphics, colours, and sound effects are culturally appropriate, and things like dates, calendars, measurement units and monetary

\footnotetext{
${ }^{4} \mathrm{~L} 10 \mathrm{~N}$ is the official appellation for the word "Localisation". The number 10 represents the number of letters found between the "L" and the "N" in the word "Localization".
} 
notations are in the correct format (Hars, 1996). In other words Localisation is the design for a locale by taking into account language, culture, religion, laws, currency, and text and number formats i.e. creating culturally biased website. Localisation includes the translation of the user interface, on-line help and documentation, and ensuring the images and concepts are culturally appropriate and sensitive.

Localising content for the first time is actually easier than the challenge of keeping it continually updated on an ongoing basis. With the web, content is continually changing, on a weekly, daily or even hourly basis. Often, changes that occur in one language must be rippled across other target languages. This process of constantly changing content must be efficiently managed.

\subsubsection{Cultural Difference Issues}

It might be useful to go through some definitions of culture before starting to highlight some differences. Henderson (Henderson, 1996) defined culture as a "manifestation of the patterns of thinking and behaviour that result through a group adaptation to its changing environment which includes other cultural groups". Hence Culture can be defined as behaviour typical of a group or class (of people). Similarly, (Martin et al., 1997) assert that culture "consists of traditional ways of doing things, traditional objects, oral traditions and belief systems that are taken for granted". (Livonen et al., 1998) defined culture to be "more than art, it is a framework to our lives. It affects our values, attitudes and behaviours. In other words we are actors in our culture and affect it".

Culture has also been defined by (Martin et al., 1997) as a way of living, thinking and learning, and as an individual dialectic. They further explained how pervasive the effect of culture is on individual perceptions, cognition and behaviour: "Each culture operates according to its own internal dynamic, its own principles, and its own written and unwritten laws. Even time and space are unique to each culture". Similarly, Hofstede (Hofstede, 1997) defined culture as "the learned pattern of thinking, feeling, acting and values, which are specific to a group or category of people". (Rice, 1999) believes that there are individual differences within the range of the generalisation of a culture. She mentions that "within a given culture there is a range of individual variations created by preferences, religion and innate differences such as gender and disabilities". Sheridan (Sheridan, 2009) defines culture as "how people from certain cultural orientations view and interpret specific images and messages".

\subsubsection{Cultural Differences}

The global nature of the Internet raises interesting questions about cross-cultural appropriateness. There are differences among cultures across the globe that dictate the way content should be presented and adapted accordingly. In other words, the manner in which the web is designed, written, and the way the information is organised may affect the users' understanding or interpretation of, or receptiveness to, the information presented. That is, many factors need to be considered when designing for an international audience; Alvin Yeo (Yeo, 1996) categorised them into overt (objective) and covert (subjective) factors. The overt factors consider tangible, straightforward and publicly observable elements. They are said to include date, time, calendars, telephone number and address formats, weekends, day turnovers, character sets, collating order sequence, reading and writing direction, punctuation, translation, units of measures and currency. Covert factors deal with the elements that are intangible and depend on culture or "special knowledge". Graphics/visuals, colours, sound, metaphors, functionality and mental models are all covert factors. Covert symbols usually have the same meaning to members of a particular culture. Thus, communication within these cultures using artefacts and symbols would be possible. There is less likelihood of misinterpretation of covert factors within a single culture. 
Different cultures may have different meanings, perceptions or metaphors for the same thing, which may depend on the context of the thing in hand. It is important to note that a users' interpretation of metaphors is based largely on the users' past and current knowledge (Murrell, 1998). An example of an area where misinterpretation may occur is screen metaphors. For example the "trash can", would not be understood by Thai users, because in Thailand, a "trash can" is a wicker basket (Sukaviriya and Moran, 1990). In the United States, the owl is a symbol of knowledge but in Central America, the owl is a symbol of witchcraft and black magic (Apple-Computer Inc., 1992). A black cat is considered bad luck in the US but good luck in the UK (Del Galdo and Nielsen, 1996). Certain covert elements may be inoffensive in one culture, but offensive in another. In most Englishspeaking countries, images of the ring or OK hand gesture may be understandable, but in France the same gesture means "zero", "nothing" or "worthless". In some Mediterranean countries, the gesture implies a man is a homosexual. Covert factors will only work if the message intended in those covert factors is comprehended in the target culture. To use any of the covert factors on a website, the website developers need to make sure that they know their users in the target cultures.

Evers and Day (Evers and Day, 1997) have also addressed the role of culture in user interface acceptance. For example, Asians prefer soft colours, fixed menus and explicit text (character)-based interfaces; while the mouse is considered the best input-device, and sound is very important. Even within Asia there are differences in interface preferences: Indonesians like soft colours, black and white displays, pop-up menus and new input technologies more than Chinese people do (Evers and Day, 1997). Barber and Badre (Barber and Badre, 1998) gave an example of the colour-culture of different countries. For example, the red colour means different things to different people: for the Chinese it means happiness; for the Japanese, anger/danger; for Egyptians, death; for the
French, aristocracy; and for Americans, danger/stop. The use of colour can also be associated with religion. For example the Judeo-Christian tradition is associated with red, blue, white, and gold; Buddhism with saffron yellow and Islam with green.

Graphic literacy (semiotics) may also affect navigation. Symbols that may be assumed to be universal may in fact not even be known to others, or may have an opposite meaning; Andrews (Andrews, 1994) points out that to an illiterate Zulu-speaking person, the "No smoking" sign means "you can smoke half a cigarette", and the "Emergency Exit" sign is interpreted as "don't run that way or you will get head, hands and feet chopped off ". A piece of research by Amory (Amory and Mars, 1994) shows that South Africans tend to represent the word "picture" with an icon of a drawing in a picture frame, while Americans are likely to draw a camera. Murrell in (Apple Macintosh, 1997) has discussed a number of highly important cultural aspects in relation to the South African user community. Also as indicated by (Hars, 1996) some cultures around the globe associate the pointing-finger cursor with thieves. The use of certain symbols, icons, or images may be offensive or even against the law in certain regions. In some parts of the world (e.g. Saudi Arabia), the celebration of Valentine's Day is punishable by law. In other parts (e.g. parts of India), it is deemed as obscene and boycotted. Celebration of the 5 th of November in Ireland is viewed as anti-Roman Catholic.

\subsubsection{Cultural Models}

A number of researchers have attempted to define the various dimensions that underpin culture. For example, Hall (Hall, 1999) distinguished cultures on the basis of a way of communicating along a dimension from "high-context" to "lowcontext". A high-context communication is one in which little has to be said or written because most of the information is either in the physical environment or within the person, while very little is in the coded, explicit part of the message. Trompenaars and Hampden-Turner (Trompenaars and Hampden-Turner, 1997) conducted research on cultural dimensions $(30,000$ 
interviews and questionnaires in 20 countries representing 47 national cultures). They distinguish culture along a number of interesting axes, including relationships and rules, group versus individual, feelings, personal involvement, status, the approach to time and attitude toward the external environment. However, it is Hofstede's dimensions of culture that are the most often quoted theories in relation to cross-cultural usability (Hofstede, 1991). He conceptualised culture as 'programming of the mind', in the sense that certain reactions were more likely in certain cultures than in others, based on differences between basic values of the members of different cultures. Hofstede carried out a study of 116,000 IBM employees distributed through 72 countries using 20 languages in 1968 and 1972. The study was based on a rigorous research design and systematic data collection (Hofstede, 1991). He proposed that all cultures could be defined through five dimensions: Power Distance (PD): The degree of emotional dependence between boss and subordinate; Individualism/Collectivism (IC): Integration into cohesive groups versus being expected to look after him/her self; Masculinity/Femininity (MF): This could be interpreted as toughness versus tenderness; Uncertainty Avoidance (UA): The extent to which members feel threatened by uncertain or unknown situations; Long/Short Term Orientation (LTO): This represented a philosophy of life that was prepared to sacrifice short-term results for long-term gain. This dimension does not discriminate across all cultures in the same way as the dimensions given above. It has been suggested that it discriminates between environmentcentric cultures and human-centric cultures. Hofstede recognised that UA was important dimension for western cultures whereas LTO was important for eastern cultures. A closely related concept to Hofstede's individualism-collectivism dimension is Rotter's (Rotter, 1966) "Locus of Control" (LC) which refers to whether individuals tend to feel that events are the result of their own actions (i.e. internal locus) or the effect of the external environment and powerful others (i.e. external locus). It has been suggested that LC influences information-seeking behaviour so that 'internals' seek more information in problem solving, although the strength of this behaviour depends very much on the situation. In contrast when individuals adopt an 'external' approach they might not generalise or learn effectively. They learn less because they believe they do not control the relationship between their behaviour and reinforcement. In Western cultures the making of plans and having them work is frequently endorsed, while in collectivist societies the focus is less on having plans work well, but more upon personal relationships. This can have many effects, including the belief a person has in his/her ability to accomplish computer tasks (Langford and Reeves, 1998).

Zahedi et al. (Zahedi et al., 2001) attempted to employ the cultural dimensions to build a conceptual model for international web design. Their model identifies the influence of cultural and individual differences in the perceived effectiveness of web design based on its usability, reliability, comprehensibility, and clarity (IBM, 2004). They adopted the cultural factors of Hofsetde (Hofstede, 1997) and they added Polychronic/Monochronic time Orientation from Hall (Hall, 1983). Hall argues that the structure of time is formulated, used, and patterned differently in different cultures and these culturally dependent temporal structures are unconsciously and invisibly woven into our everyday activities, deeply influencing how we work and think. Polychronic cultures prefer doing many things at a time, stress involvement with people and completion of transactions rather than adherence to schedules, emphasise commitments to people and lifetime relationships, and rely on the situational context of the message (Hall, 1983). Monochronic cultures prefer doing one thing at a time, compartmentalise relationships and tasks according to strict time schedules, value promptness and adherence to plans, and rely on communications in which most of the information must be included in the message itself with details clearly spelled 
out (Hall, 1983). The researchers are interested, therefore, in conducting studies with target users to determine the extent to which cultural factors do actually affect the international website usability and accessibility.

\section{Research Methods}

The primary question of this research is "What are the most influential usability considerations when localising websites and do they differ from one culture to another?" In pursuing the answer to this question, the following research propositions were explored, based on the deductive/inductive analysis of the surveys, which was conducted among the users' and designers' communities:

- Information content of a website should be sensitive to the religious and moral beliefs of the target users.

- Navigation styles and positioning should be sensitive to language and the user's real world experience (e.g. symbols and metaphors).

- Information content and page design should be sensitive to language directionality of the target users.

- Images and colours of a website should be culturally appropriate to the target users.

- In addition, some common features are important to most cultures for example: 1) the customer services, navigation systems, personalisation, security assurance and accessibility often influence users' online experience; 2) design consistency improves users' online experience and hence user satisfaction.

This research starts, first with a literature review, including different approaches to web usability, leading to an investigation of whether there exist effective guidelines for website design and implementation. The limitations and drawbacks of existing web usability guidelines were explored. Effort was made to distinguish between the web usability guidelines and ISO International Standards for software usability and to explore whether the latter can still hold for the use of web applications. Two comprehensive surveys are reported, covering: 1) the usability evaluation methods for web interfaces and 2) the existing commercial tools that analyse websites for web usability and accessibility, illustrating what kind of automatic tests they perform.

This study discusses, in varying degrees, issues such as: how users read on the web and what language level to use on the web; what writing style authors should use on their web pages; how to accommodate people with disabilities, and those for whom English is not their first language; whether it is possible to assume a certain educational level when writing for the web; whether it is possible to use readability indexes to measure the readability of a web page; and whether it is better to localise or to internationalise a commercial website.

Based on the literature and the previous work of professionals in the field, a conceptual framework of the general issues that influence user interface design and usability was formulated. The purpose of which was to explore the international users' expectations of localised websites, and to uncover how designers should design the user interface of the international websites, the constructs of the framework were used in the research instruments.

To achieve the research objectives, a multimethods study was conducted with subjects who had little or no experience with English websites and who may be using the web in their own language. Ideally this study was intended to cover a global sample but due to logistics and time restrictions, it focussed on the Arabic cultural background. In addition a control group was used comprising of almost an equal number of English men and women. This paper also aims to determine whether different users (Arabs in particular) read sites differently or react differently to interface design elements such as colour, graphics and arrangement. For instance, do Arabic speaking users have different preferences for the placement of elements on the page due to the fact that the Arabic language is read from right to left, in contrast to the English language, which is read from left to right? 
A questionnaire was used as an instrument to survey the users from different cultures (Arab vs. British). Another questionnaire survey was conducted among website designers designing for both the Arabic and British markets. Both surveys were followed by a clarification task, where the researchers contacted some of the participating users and designers to clarify any ambiguous feedback. In order to obtain a clearer, more detailed picture of the design firms' thinking and practice, two case studies were carried out, in an Arab and in a UK company respectively. After analysing the data and developing the framework, the researchers assessed its validity by conducting the following experiment: Evaluate a website using the developed framework, redesign the website, re-evaluate its usability and measure the time (performance) taken to perform the same tasks before and after the redesign. Also the users were asked to rate some identified usability features and to provide any general comments in order to enhance the website performance and usability.

The end product of this study was the production of a consolidated framework for designing usable localised websites, combined with a set of recommendations for those user interface designers designing for international audiences, to help them to assess the appropriateness of their designs for the targeted audience.

\section{The Framework Construction}

(Sommerville, 2001) highlighted a number of software development process models including the waterfall model, evolutionary, formal systems, reuse-based, incremental and spiral development. These models are intended for software rather than website development, and they do not take into account the contextual use per se. The proposed framework aims to remedy this shortcoming of the existing process models. After conducting the Users' Survey and data analysis (Al-Badi, 2005), the initial draft of the Cultural User Interface (CUI), Country and Computing Environment Profiles were made, for both Oman and the UK. Both, the Designers'
Survey (Al-Badi, 2005) and the Case Studies (Al-Badi, 2005) helped to enhance and consolidate these profiles. These profiles were extracted and compiled to be used as a reference for web designers in the mentioned countries. Moreover, it can also be adapted to other countries. The final versions of these profiles are available in (Al-Badi, 2005). The creation of such profiles by the detailed studies performed during the current research aims to help the usability experts and web designers to create culturally appropriate, accessible and usable websites as well as enhancing the usability of already-built websites. This is because these profiles provide all the materials necessary for creating a "cultural usability checklist", in this case for the Oman and British markets. The "cultural usability checklist" for Oman can be adapted for any of the Arab countries with slight modifications, due to the striking similarities between them. The "cultural usability checklist" deals with the most essential issues of the "user interface" in relation to both technical and cultural aspects. A short version of the "cultural usability checklist" is shown in the Table 1. It does not tell the designers how to do things but rather what to do to achieve a culturally usable website. A detailed version of the "cultural usability checklist" for Oman is provided in (Al-Badi, 2005). After constructing the framework based on the findings of the users' and designers' surveys, case studies, as well as on the experience of the researchers and other IT professionals and academics (as highlighted in the recent literature), the "framework for designing usable localised websites" was evaluated for practicality and usefulness an then the framework was modified to reflect the evaluation findings. The improved version of the framework is depicted in Figure 2. 
Table 1: A short Version of the Cultural Usability Checklist- Oman

\begin{tabular}{|c|c|c|}
\hline No & Feature & Y-N-N/A \\
\hline & General Site Issue & \\
\hline 1 & Adherence to teachings of Islam & \\
\hline 2 & Adherence to Arabic culture belief systems & \\
\hline \multirow[t]{2}{*}{3} & The website is bilingual (Arabic and English) & \\
\hline & Graphics & \\
\hline 4 & Human figure to be appropriately dressed & \\
\hline \multirow[t]{2}{*}{5} & Warning when a link leads to a page with large graphics & \\
\hline & Page Length, Scrolling and Dividers & \\
\hline \multirow[t]{2}{*}{6} & Vertical scrolling bar positioned on the left of the page & \\
\hline & Navigation System & \\
\hline \multirow[t]{2}{*}{7} & Navigation bar position on top and possible to the right hand side of the page. & \\
\hline & Writing and Readability & \\
\hline 8 & Coloured text & \\
\hline \multirow[t]{2}{*}{9} & Light text colours on dark background & \\
\hline & Colours & \\
\hline \multirow[t]{2}{*}{10} & Cold colours such as blue and green & \\
\hline & Placement and Alignment of Elements & \\
\hline 11 & Text must be aligned right & \\
\hline \multirow[t]{2}{*}{12} & Important content can be place to the top right corner of the page & \\
\hline & Data Entry Form Usage & \\
\hline \multirow[t]{2}{*}{13} & Form fields clearly labelled with appropriate text information & \\
\hline & Country Profile & \\
\hline \multirow[t]{2}{*}{14} & Data Format (Address, Currency and Date) & \\
\hline & Computing Profile & \\
\hline 15 & Browser type and version & \\
\hline
\end{tabular}



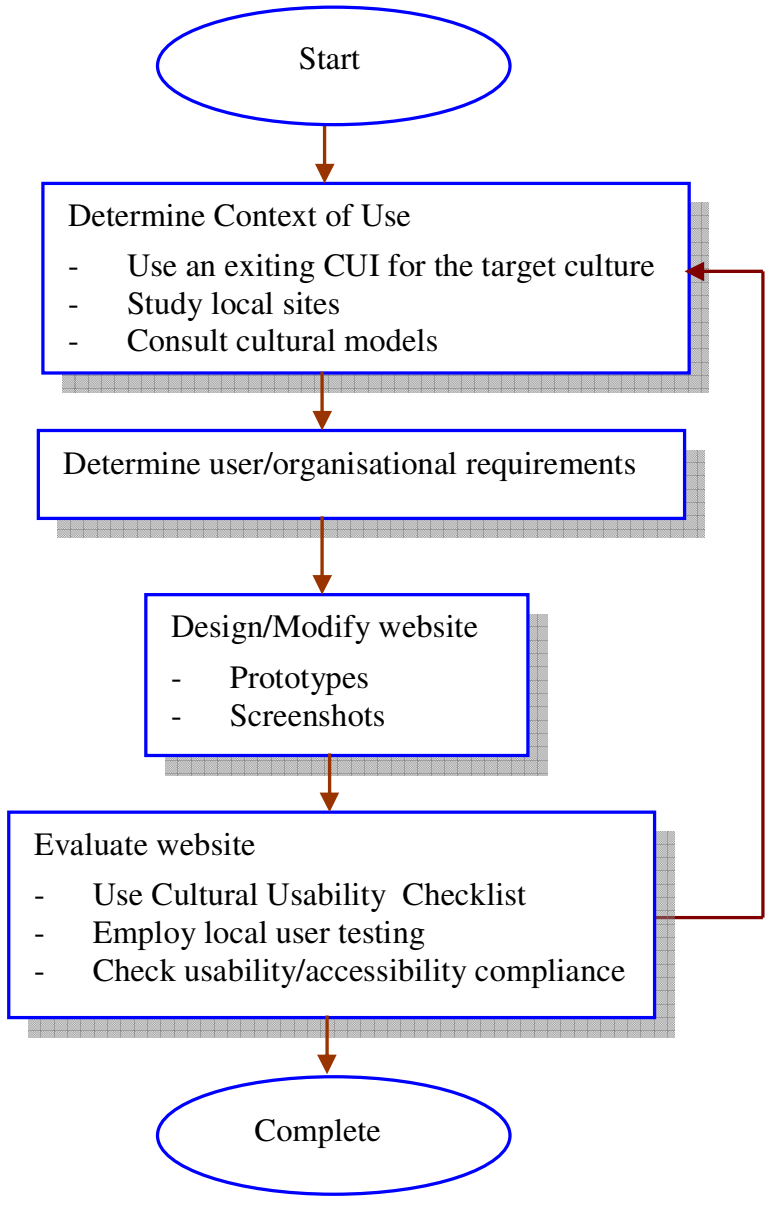

Figure 2: An Improved Framework for Designing Localised Websites 


\section{Research Findings}

The main findings resulting from the Users' and Designers' surveys, the Case Studies and evaluation of the website both before and after redesigning can be summarised as follows:

The necessity to understand the target culture and the needs of the business commissioning the website: The surveys and website evaluations confirmed the fundamental need to understand the nature of the business involved and equally important, especially in the case of Arab countries - the culture of the target audience i.e. to respect the teachings of Islam and Arabic cultural values. The British made few comments about cultural values (but showed some irritation with Americanisation). The fact they considered British currency and measurements important however, was an indication that they realised the need to be focused on the needs of their customers.

This research showed that there were some common preferences between the cultures. This might be due to the fact that the surveyed Omani sample were able to read in English, which is taught from year 1 in Omani schools, with special emphasis on it in the science stream. However, the results of the surveys and other investigations also clearly showed the importance of localising websites for the target audience, especially because of the language related issues, data format (e.g. currency, month names and address format) and religious beliefs.

According to Hofstede (Hofstede, 1991) different countries have different characteristics and this is reflected in their preferences. Amara and Portaneri (Amara and Portaneri, 1999) stated that "different country dependencies must be implemented" and they gave as an example the problem of the names of months which differ in Arab countries located in North Africa from the eastern Arab countries. One noticeable difference between the two cultures surveyed in this study is that when designing for Arab countries, the website has to be bilingual. This is probably due to the fact that there are minorities, and many foreign workers in these countries who do not speak Arabic.

Design consistency: The evidence of the surveys and the case studies as well as the website evaluations emphasised the importance of consistency in navigation, layout, interaction, graphics and colours throughout all aspects of a website. This finding supports the many calls by professionals (Nielsen, 1997a) to have a consistent design of different pages throughout a website.

Limited Use of Usability/Accessibility Tools/Guidelines: A surprising result of the surveys was the limited use made of usability and accessibility tools and guidelines by the designers in both countries. The British occasionally used W3C HTML validation tools and to a lesser extent, Bobby, but seldom other tools. The Arab designers used none of the listed tools. The British used some guidelines, in particular, W3C WCAG. This study also discovered that it is not possible for website designers to use one set of guidelines in all cases especially when designing websites for an international market. Furthermore, requirements for all websites differ for obvious reasons. These include the purpose of the website, whether it is intended to be commercial, educational, news, entertainment etc., the speed of the Internet connection, the abilities of the target users and - not least important - the culture of the audience. This explains why designers often do not use any particular set of guidelines but rather, tend to rely on their intuition and experience. It is better to have a framework that guides the process of designing websites which is applicable in all cases as is proposed in this thesis.

\subsection{Recommendations for Website designers}

Armed with the knowledge gained from this research and its findings together with lessons learnt from previous research in this field, the researchers would like to provide some recommendations for web designers to help in the creation of successful (i.e. usable) localised websites. These recommendations are as follows:

- Know the Target Audience: to fully understand the target audience adopt the framework described in this paper. It is clear that using this framework during the website development lifecycle should lead to a successful outcome. Remember if customers get offended or intimidated once while they are at your website they 
may not come back again since all the competitors are but a mouse- click away. In addition, an unsatisfied customer may spread the word that this site is poor.

\section{- Usability/Accessibility}

Tools/Guidelines: Although it was discovered during this research that only limited use was made of usability and accessibility tools and guidelines by designers in both countries, the use of these aids is now recommended by usability experts and in order to comply with government requirements in many countries ((Al-Badi, 2005))

- $\quad$ Culturally Usable Websites: Do not try to design "usable cross-culture" websites, because this approach implies "one-size-fits-all". This is clearly impossible due to the fact that people's preferences are different as this research showed. The right approach is to create a "culturally usable" website where designers localise websites for each of the target cultures, taking into account all the overt and covert factors that need to be considered when designing for such cultures.

- $\quad$ Target Users Involvement: As indicated in the enhanced framework, integrating local users into all the design phases will help to create a website that suits them which is also the designers' objective. Remember that many people can design websites but not many can design successful ones. This involvement would enable designers to avoid crises similar to the "dot com" crisis.

- Design Consistency: Create an exclusive layout and a style for handling website text and graphics which can then be applied consistently to build rhythm and unity throughout the pages of the website. Repetition is not boring; it gives the website a consistent graphic identity that creates and then reinforces a distinct sense of "look and feel" and makes the website memorable. A consistent approach to layout and navigation allows readers to adapt quickly to the website design and to confidently predict the location of information and navigation controls across the pages. Design consistency issues have been emphasised throughout the different stages of this research for its importance and criticality for creating successful websites.

- Website Periodical Maintenance: there must be a continuous/periodical maintenance of the website to cope with the rapid changes in terms of content and technology.

\subsection{Achievement of Objectives}

This study was able to meet its overall aim, which was to explore the design of websites for different cultures. Firstly, the researchers gathered a wealth of information on the issues that influence user interface design and usability. An outline of current and relevant literature with regards to cultural usability and user interface design was provided. This included a) usability/accessibility tools and guidelines; b) usability evaluation methods; c) readability formulas; d) globalisation: internationalisation and localisation; e) cultural models and Technology Acceptance models. After conducting different research methods, the researchers were able to develop three profiles (the Cultural User Interface, Country and Computing Environments). These three profiles can act as references for web designers, making their tasks easier and more likely to be successful, especially when designing for Arab and British cultures. In Addition, this research effort together with the accumulated professional experience enabled the researchers to build a comprehensive framework for designing usable localised websites. This framework proved to be useful in guiding the successful design process that was demonstrated in this paper.

Moreover, this research highlighted the most influential usability considerations when localising websites (for details see (Al-Badi, 2005)). It also showed that the studied cultures although they may have some common usability preferences, do differ in the importance they assign for each usability attribute. In particular, the research proved that the following statements were true:

- The information content of a website should be sensitive to the religious and moral beliefs of the target users. In this regard, it was noticed that both the Arab users and designers placed great emphasis on the fact that the website needs to adhere and respect the religious beliefs and moral values of the target culture. 
○ Navigation styles and positioning should be sensitive to language and the users' real world experience. It was proved that the directionality of the mothertongue language influenced of the preference of navigation positioning (left or right hand side). Also it should not be assumed that metaphors are understood in all cultures, e.g. the current symbol for "home" (a simplistic depiction of a red roofed house) is not recognised as such in all cultures who would then fail to understand the "home" instruction.

$\circ \quad$ Images and colours of a website should be culturally sensitive to the target users. This was clear from the emphasis that Arab respondents placed on the question of human figure being appropriately dressed and their preference for the use of the colour green, symbolic of Islam.

- In addition, some common features are important to most cultures for example: 1) good customer services, navigation systems, personalisation, security assurance and accessibility often influence users' online experience; 2) design consistency improves users' online experience and hence user satisfaction. These issues were discovered from the different methods used throughout the research.

All of this emphasises the point that international websites must take users' cultural background into account so users are not disadvantaged and the website is more likely to be successful.

\subsection{Research \\ Contributions}

General

Different parties might benefit from the research findings, outcome and the developed approach (i.e. the framework, CUI, computing and country profiles as well as the usability checklist), for example, researchers can use the outcome of this research to build on and to conduct further research. Designers/evaluators and website owners attempting to design, develop, evaluate and maintain successful websites not only for the Arabic and British markets but also for targeting other cultural groups especially the Arab countries with slight modification to the CUI/Checklist. Software/web designers can use it in the process of personalisation/customisation of their products and it can act as building block for a localisation process in other countries. Similarly, website owners can benefit greatly from it by realising that they need to consider cultural issues in website usability when localising their websites.

The research findings contribute to the general field of software/web localisation and personalisation. They also provide academics and industry with information on the degree to which cultural localisation is needed to ensure usability. In addition, they highlight the extent to which users' cultural background and perceptions influence their preferences and hence the acceptance of the virtual world of online user interfaces.

Furthermore, by contributing to the improvement of the design and quality of a website, this research will promote a better relationship between the customers and website owners.

In addition, the instruments used in this research could be adapted to enable their use in different countries worldwide. Furthermore, the effort of building similar profiles (Cultural User Interface, Collective and Computing Environments) for other countries holds considerable potential for localisation companies and others to create reusable libraries that would provide set of useful building blocks for future commercial website localisation projects.

Another major contribution is the progress made toward becoming a "Usability Professional". Nielsen stated that "to reach the goal of making technology truly suited for humans; the world will need about half a million new usability professionals over the next 20 years. The sooner their training begins, the better off we'll all be"(Nielsen, 2002). He also claimed that a successful usability career requires some theoretical knowledge, but mainly rests on brainpower and many years' experience testing and studying users. The only way to gain that experience is to start now.

\subsection{Suggestions for Further Research}

It would be of great interest to conduct further research in this field using the same countries but taking into account a 
different sample size and type. Translating the research instruments especially the users' questionnaire into Arabic might have different results. It would be interesting to see what results might be obtained in this way.

It would be a good project for researchers worldwide to cover other cultures, creating different CUI, computing environment and country profiles ultimately to build a complete database of world audience needs and expectations of the website targeting them. It could be feasible to create one version CUI, computing environment and country profiles with amendments for each specific country. Another possibility would be to study different Arabic subcultures (e.g. Oman, UAE, and Saudi Arabia), or study two widely contrasting cultures: European (e.g. UK, France, Italy and Germany) and Arabic (e.g. Oman, UAE and Saudi Arabia).

It would also be interesting to consider each specific domain (e.g. education, commerce, news, etc). This process would allow the creation of what might be called "Domain User Interface".

Another possibility may be to try building a unified set of metaphors (or symbols) to be used on websites worldwide that are common to all countries, fully understood and do not offend anybody. This would resemble what traffic engineers/police managed to do in regards to the traffic/road rules or the "Highway Code" for road navigation and might reduce the work of localising websites since many features/icons would be the same.

\section{Concluding Remarks}

The global nature of the web and the differences among cultures across the globe dictate the way content should be presented and adapted. Therefore, there is no way to have a perfect single design for all possible users (universal usability or inclusive design). Some user interface elements such as certain graphics and images may offend one group of users on cultural or religious grounds. Naturally, it is important not to offend users but rather to use culturally neutral graphic representations or metaphors. Content localisation involves the process of adapting the information according to specific linguistic, cultural and business rules for a given target audience. Hence, it is not enough to be multilingual; international websites have to be multicultural. While website localisation might add additional cost/burden on the maintenance budget of a commercial company, it will ensure websites usability, flow and acceptability for the intended users. The researchers believe that localisation gives a website the ability to attract surfers and in many cases, convert them to loyal customers.

The proposed approach in this paper makes the localisation process more effective and more likely to achieve its objectives. It also takes into account the rapid changes in the technology and their deliveries as well as to advancements in users' knowledge and expectations.

\section{References}

AL-BADI, A. 2002. Readability Indexes/

Formulas. Norwich: School of Computing

Sciences, University of East Anglia.

AL-BADI, A. H. 2005. A Framework for Designing Usable Localised Websites. PhD Thesis, University of East Anglia.

ALEXANDER, D. 2009. Web Usability [Online]. Available: http://www.its.monash.edu.au/web/slide shows/usability/slide2-5.html [Accessed 10/10/09].

ALLEN, J. 2002. The Writing on the Web [Online]. Available: http://hotwired.lycos.com/webmonkey/9 9/32/index0a.html?tw=commentary [Accessed 9/06/05].

AMARA, H. \& PORTANERI, F. 1999. Arabization of Graphical User Interfaces. In: DEL GALDO, E. \& NIELSEN, J. (eds.) International User Interface. New York: John Wiley.

AMORY, A. \& MARS, M. Year. Evaluation of Efficacy of Multimedia Learning: Project development and strategies. In: The international conference on ComputerAssisted Education and Training in Developing Countries, 1994 University of South Africa, Muckleneuk, Pretoria. 1-6. 
ANDREWS, S. J. Year. Some Cultural and Perceptual Implications of Courseware Development and the Use of Technology within a Multi-cultural, Multilingual Society (a cautionary tale). In: The International conference on ComputerAssisted Education and Training in Developing Countries, 1994 University of South Africa, Muckleneuk, Pretoria. 7-13.

APPLE-COMPUTER INC. 1992. Human Computer Interface Guidelines, Reading, Mass., Addison Wesley.

APPLE MACINTOSH. 1997. Macintosh Human Interface Guidelines [Online]. Available:

http://developer.apple.com/documentatio $\mathrm{n} / \mathrm{mac} /$ HIGuidelines/HIGuidelines-2.html [Accessed 9/06/05].

BARBER, W. \& BADRE, A. Year. Culturability: The Merging of Culture and Usability. In: the 4th Conference on Human Factors and the Web, June 1998 1998 Basking Ridge, NJ.

BECKER, S. \& BERKEMEYER, A. H. 2001. A Web Usability Assessment Model and Automated Toolset. IEEE Software.

BECKER, S. A. 2002a. An Exploratory Study on Web Usability and the Internationalization of U.S. E-Businesses. The Journal of Electronic Commerce Research, 3, 265-278.

BECKER, S. A. 2002b. An Exploratory Study on Web Usability and the Internationalization of US E-businesses. Journal of Electronic Commerce Research, 3, 265-278.

BECKER, S. A. 2002c. Web Accessibility for Ethnic Aging Adults: UsabilityEnforcer [Online]. Available: http://www.cba.nau.edu/beckera/Accessibility/usabilityenforcer.html [Accessed 2002].

BECKER, S. A. \& CRESPO, F. Year. A Multicultural Perspective on Digital Government Usability. In: The 1st International Conference on Universal
Access in Human-Computer Interaction, August 20012001 New Orleans, Louisiana. BEIREKDAR, A., VANDERDONCKT, J. \& NOIRHOMME-FRAITURE, M. Year. A Framework and a Language for Usability Automatic Evaluation of Web Sites by Static Analysis of HTML Source Code. In: 4th Int. Conf. on Computer-Aided Design of User Interfaces CADUI'2002, May 15-17 2002 Valenciennes, France. Kluwer Academics Pub., Dordrecht, 337-348.

BOLDYREFF, C. Year. Determination and Evaluation of Web Accessibility. In: The Eleventh IEEE International Workshops on Enabling Technologies: Infrastructure for Collaborative Enterprises (WETICE'02), 2002 Pittsburgh, PA, USA.

BORGES, J. A., MORALES, I. \& RODR?GUEZ, N. J. 1996. Guidelines for designing usable World Wide Web pages, New York, NY, USA, ACM Press.

BRAJNIK, G. Year. Automatic web usability evaluation: what needs to be done? In: 6th Conference on Huaman Factors \& the Web, 2000.

BRINCK, T., GERGLE, D. \& WOOD, S. D. 2002. Usability for the Web, Morgan Kaufman.

BROWN, J. 2002. Accessibility Monitor [Online]. Available:

http://www.cpcug.org/user/houser/secti on508/accessibility_monitor.htm [Accessed 01/03/04].

COMPUTER WEEKLY 2001. Why your site should have disabled access. Computer Weekly.

DAVIS, F. D. 1993. User Acceptance of Information Technology: System Characteristics, User Perceptions and Behavioral Impacts. Int. Journal ManMachine Studies, 38, 475-487.

DEL GALDO, E. \& NIELSEN, J. (eds.) 1996. International User Interfaces, New York: John Wiley. 
DILLON, A., MCKNIGHT, C. \& RICHARDSON, J. 1992. Reading from Paper versus Reading from Screen: A critical Review of the Empirical Literature. Ergonomics, 35, 1297-1326.

EVERS, V. \& DAY, D. 1997. The role of culture in interface acceptance. In: HOWARD, S. (ed.) Human Computer Interaction INTERACT'97. London: Kluwer Academic Publishers.

FEDERAL COMMUNICATIONS

COMMISSION. 2004. Section 255:

Telecommunications Access for People with Disabilities [Online]. U.S. Federal Communications Commission. Available: http://www.fcc.gov/cgb/consumerfacts/s ection255.html [Accessed 20/12/02].

FLANDERS, V. \& WILLIS, M. 1998. Web Pages That Suck. SYBEX, San Francisco, CA. FORRESTER RESEARCH. 2003. Forrester Research [Online]. Available: http://www.forrester.com/home/ [Accessed 01/03/04].

GRAVES, S. 2001. Check sites for 508 with audit-edit tools. Government Computer News, 20.

HALL, E. T. 1983. The Dance of Life:The Other Dimension of Time, Garden City, NY, Anchor.

HALL, E. T. 1999. Beyond Culture, Anchor Books.

HARS, A. 1996. Localizing software is not just a multilingual issue; it's also multicultural. Byte.

HENDERSON, L. 1996. Instructional Design of Interactive Multimedia: A Cultural Critique. Journal of Educational Technology Research and Development (ETR\&D), 44, 85-104.

HILL, A. L. 1997. Readability of Websites with Various Foreground/Background Colour Combinations, Font Types and Word Styles [Online]. Available:
http://hubel.sfasu.edu/research/AHNCUR. html [Accessed 9/06/05].

HOFSTEDE, G. 1991. Culture and Organization: Software in the Mind, London, McGraw-Hill.

HOFSTEDE, G. 1997. Culture and Organization: Software in the Mind, London, McGraw-Hill.

HOWER, R. 2009. Web Site Test Tools and Site Management Tools [Online]. Available: http://www.softwareqatest.com/qatweb1. html [Accessed 10/10/09].

HURST, M. 1999. Holiday '99 E-Commerce. Creative Good, Inc.

IBM. 2004. IBM Ease of Use - Web design guidelines [Online]. Available: http://www3.ibm.com/ibm/easy/eou_ext.nsf/Publish/ 572 [Accessed 11/02/05].

INFORMATION SOCIETY. 2002. EU Web Accessibility Initiative [Online]. Available: http://europa.eu.int/information_society/ topics/citizens/accessibility/index_en.htm [Accessed 2002].

ISO 9126. 2002. ISO9126 [Online].

Available:

http://www.isaca.org.za/Iso9126.htm

[Accessed 11/11/2002 2002].

IVORY, M. Y. \& CHEVALIER, A. 2002. A Study of Automated Web Site Evaluation Tools. Technical Report UW-CSE-02-10-01.

IZAR.COM. 2002. Izar.com [Online]. Available: http://www.izar.com/ [Accessed 12/02/02 2002].

KEEVIL, B. 1998. Measuring the usability index of your Web site, New York, NY, USA, Series-Proceeding-Article.

KIVINIEMI, M. 2000. Improving product usability with user-centred methods. Master of Science, Helsinki University of Technology. 
LANGFORD, M. \& REEVES, T. E. 1998. The relationships between computer selfefficacy and personal characteristics of the begining information systems student. Journal of Computer Information Systems, 38, 41-44.

LEE, A. T. 1999. Web Usability. SIGCHI Bulletin, 31, 38-40.

LETOURNEAU, C. 2003. Accessible Web Design - a Definitiion [Online]. Available: http://www.starlingweb.com/webac.htm [Accessed 1/7/2005].

LIVONEN, M., SONNENWALD, D. H., PARMA, M. \& POOLE-KOBER, E. 1998. Analysing and understanding cultural differences: Experience from education in library and information studies [Online]. Available: www.ifla.org/IV/ifla64/077155e.htm [Accessed 11/10/2009].

LYNCH, P. J. \& HORTON, S. 1999. Web Style Guide: Basic Design Principles for Creating Web Sites, Yale University Press.

MARTIN, J. N., NAKAYAMA, T. K. \& FLORES, L. A. (eds.) 1997. Readings in Cultural contexts, California: Mountain View: Myfield Publishing Company.

MILLER, D. 2004. How Not to Write for the Web [Online]. Available:

http://www.netscape.com/computing/we bbuilding/studio/feature19980827-1.html [Accessed 9/05/05].

\section{MINISTRY OF SOCIAL DEVELOPMENT 1995. Oman 1995 Census.}

MONTEREY TECHNOLOGIES INC 1996. Resource Guideline for Accessible Design of Consumer Elements.

MORKES, J. \& NIELSEN, J. 1997a. Concise, Scannable, and Objective: How to write for the Web [Online]. Available:

http://www.useit.com/papers/webwritin g/writing.html [Accessed 10/10/2009 2009].
MORKES, J. \& NIELSEN, J. 1997b. Concise, Scannable, and Objective: How to write for the Web [Online]. Available:

http://www.useit.com/papers/webwritin g/writing.html [Accessed 10/10/2009].

MURRELL, K. A. 1998. Human Computer Interface Design in a Multi-Cultural MultiLingual Environment. University of Natall.

NIELSEN, J. 1994. Usability Engineering, Academic Press.

NIELSEN, J. 1997a. 10 steps to better usability. Byte, 22, 32-32.

NIELSEN, J. 1997b. How Users Read on the Web [Online]. Available: http://www.useit.com/alertbox/9710a.ht $\mathrm{ml}$ [Accessed 10/10/09].

NIELSEN, J. 1997c. How Users Read on the Web [Online]. Available: http://www.useit.com/alertbox/9710a.ht $\mathrm{ml}$ [Accessed 10/10/09 2009].

NIELSEN, J. 1999. Designing Web Usability: The Practice of Simplicity, New Riders Publishing.

NIELSEN, J. 2002. Becoming a Usability Professional [Online]. Available: http://www.useit.com/alertbox/2002072 2.html [Accessed 11/10/2009].

NIELSEN, J. 2005. Top Ten Guidelines for Homepage Usability [Online]. Available: http://www.useit.com/alertbox/2002051 2.html [Accessed 12/03/05].

NIELSEN, J. \& MACK, R. 1994. Usability Inspection Methods, New York, John Wiley and Sons, Inc.

NIST. 2004. WebSAT Static Analyzer Tool [Online]. National Institute of Standards and Technology. Available: http://zing.ncsl.nist.gov/WebTools/WebS AT/overview.html [Accessed 10/03/04 2004]. 
PACIELLO, M. 2000. Web Accessibility for People with Disabilities, CMP Books.

PREECE, J., ROGERS, Y., SHARP, H., BENYON, D., HOLLAND, S. \& CAREY, T. 1994. Human-computer interaction, Workingham, England, Addison-Wesley.

RICE, J. C. Year. Cultural differences: Designing Web Materials for a Global learning Community. In: the ED-MEDIA 99--World Conference on Educational Multimedia, Hypermedia \& Telecommunications, June 19-24 1999 1999 Seattle, Washington.

RIYADH CITY REPORTER. 2004. The problem of 720, 000 disabled in KSA [Online]. LahaOnline magazine(Arabic virsion). Available: http://lahaonline.com/People/a4-10-032004.doc_cvt.htm [Accessed 10/3/2004].

ROTTER, J. B. 1966. Generalised expectancies for internal versus external control of reinforcement. Psychological management, 80, 1-28.

SCAPIN, D., LEULIER, C., VANDERDONCKT, J., MARIAGE, C., BASTIEN, C., FARENC, C., PALANQUE, P. \& BASTIDE, R. Year. A Framework for Organizing Web Usability Guidelines. In: 6th conference on Human Factors \& the Web, 2000.

SHERIDAN, E. F. 2009. Cross-cultural web site design: Considerations for developing and strategies for validating locale Appropriate on-line content [Online]. MultiLingualComputing, Inc. Available: http://www.multilingual.com [Accessed 11/10/2009].

SHNEIDERMAN, B. 1998. Designing the User Interface: Strategies for Effective Human-Computer Interaction, Boston, MA, Addison-Wesley.

SHNEIDERMAN, B. 2000. Universal Usability. Communications of the ACM, 1.

SMILLIE, D. 2001. Access for all [Online]. Available:
http://www.ja.net/conferences/JUSW/20 01/D.Smillie.pdf [Accessed 9/05/4].

SOMMERVILLE, I. 2001. Software Engineering, London, Addison Wesley.

SPOOL, J., SCANLON, T., SCHROEDER, W., SNYDER, C. \& DEANGELO, T. 1999. Web Site Usability : A Designer's Guide, San Francisco, Morgan Kaufmann Publishers.

SPOOL, J. M. \& SCANLON, T. Year. Measuring Website Usability. In: Computer Human Interaction, 1997.

SUKAVIRIYA, P. \& MORAN, L. 1990. User Interface for Asia. In: NIELSEN, J. (ed.) Designing User Interfaces for International Use. New York: Elsevier.

THATCHER, J. W. 2002. JimThatcher.com: Evaluation and Repair [Online]. Available: http://jimthatcher.com/erx.htm [Accessed 13/10/02].

THOMASON, L. 2009. Writing for The Web [Online]. Available: http://www.netmechanic.com/news/vol4 /design_no10.htm [Accessed 10/10/09].

TROMPENAARS, F. \& HAMPDEN-TURNER, C. 1997. Riding the Waves of Culture: Understanding Cultural Diversity in Business, McGraw-Hill.

UK RNIB. 2002a. Accessible Web Design: hints for designing accessible websites [Online]. Available: http://www.rnib.org.uk/digital/hints.htm [Accessed 01/03/04].

UK RNIB. 2002b. Campaign for Good Web Design [Online]. Available: http://www.rnib.org.uk/digital/ [Accessed 10/03/04].

UNISCAPE. 2002. Uniscape [Online]. Available: http://www.uniscape.com/ [Accessed 2002]. 
UNIVERSITY OF ROCHESTER. 2009. Web Usability Guidelines [Online]. Available: http://www.rochester.edu/ATS/Documen tation/WebHelp/usability.html [Accessed 10/10/09].

US SECTION 508. 2009. Section 508 of the rehabilitation Act Amendments of the 1998 [Online]. Available:

http://www.section508.gov/index.cfm?Fu seAction=Content\&ID=14 [Accessed 10/10/09].

USABILITY.GOV. 2002. Usability.gov [Online]. Available: http://usability.gov/ [Accessed 2002].

USABLENET.COM. 2002. LIFT: for Accessibility and Usability Testing [Online]. Available: http://www.usablenet.com [Accessed 20/05/02 2002].

VANDERDONCKT, J. 1999. Development Milestones towards a Tool for Working with Guidelines. Interacting with Computers, 12, 81-118.

W3C. 2002a. W3C HTML validation tools [Online]. Available:

http://validator.w3.org/ [Accessed 12/02/02].

W3C. 2002b. Web Content Accessibility Guidelines 2.0 [Online]. Available: http://www.w3.org/WAI/GL/WCAG20/ [Accessed 20/12/03].

WATCHFIRE. 2002. Bobby: A Verifier of Web Site Accessibility [Online]. Available: http://www.watchfire.com/products/bob by.asp, http://www.cast.org/bobby/ [Accessed 21/02/02].

WEBAIM. 2009. Products and Tools [Online]. Available: http://www.webaim.org/products/evalan drepair/commercial [Accessed 10/10/09]. WEITZEL, D. 2003. Who's reading your writing? [Online]. Available: http://www.ext.colostate.edu/pubs/octne ws/oc030602.html [Accessed 2/04/03].
YEO, A. 1996. World-Wide CHI: Cultural User Interfaces, A Silver Lining in Cultural Diversity. SIGCHI, 28, 4-7.

ZAHEDI, F., PELT, W. V. V. \& SONG, J. 2001. A Conceptual Framework for International Web Design. IEEE Transactions on Professional Communication, 44, 83-103 